\title{
Reconstructing the historical spatial land use pattern for Jiangsu Province in mid-Qing Dynasty
}

\author{
JIN Xiaobin ${ }^{1,2}$, PAN Qian ${ }^{1}$, YANG Xuhong ${ }^{1}$, BAI Qing ${ }^{2}$, ZHOU Yinkang ${ }^{1,2}$ \\ 1. School of Geographic and Oceanographic Sciences, Nanjing University, Nanjing 210023, China; \\ 2. Natural Resources Research Center of Nanjing University, Nanjing 210023, China
}

\begin{abstract}
This study is proposed to reconstruct a high-resolution spatial distribution of historical land use pattern with all land use types to overcome low-accuracy and/or the monotonic land use type in current historical land use reconstruction studies. The year of 1820 is set as the temporal section and the administrative area of Jiangsu Province is the study area. Land use types being reconstructed include farmland, residential land (including both urban land and rural residential land), water body, and other land (including forest land, grassland, and unused land). Data sources mainly refer to historical documents, historical geographic research outcomes, contemporary statistics, and natural environmental data. With great considerations over regional natural resources and social and economic conditions, a few theoretical assumptions have been proposed to facilitate the adjustment on prefecture farmland, urban land, and rural residential land. Upholding the idea that the contemporary land use pattern has been inherently in sequence with the historical land use pattern as well as the land use pattern shall be consistent to its accessibility, this study reconstructs the land use pattern in Jiangsu Province in 1820 with $100 \mathrm{~m} * 100 \mathrm{~m}$ grids based on accessibility analysis and comprehensive evaluation. The outcome has been tested as valid by regionalization and correlation analysis. The resulted spatial distribution shows that back in 1820 in Jiangsu Province: (1) farmland, urban land, rural residential land, water body, and other land take about $48.49 \%, 4.46 \%, 0.16 \%, 15.03 \%$, and $31.86 \%$ of the total land area respectively; (2) the land use pattern features high proportion of land in farming while low-proportion land in non-farming uses while population, topography, and the density of water body lead to great spatial variations; and (3) the reconstruction methodology has been tested as reasonable based on significant positive correlations between 1820 data and 1985 for both farmland and rural residential land at the prefecture level.
\end{abstract}

Keywords: land use; grid, reconstruction; mid-Qing Dynasty; Jiangsu Province

Land cover is the most obvious landscape indicator of terrestrial ecosystems. It is jointly affected by human land-use activities and natural processes (Li, 1996). Meanwhile, land cover serves as the most direct signal for characterizing the influence of human activities on terrestrial ecosystems. Land cover provides a link between human economic activities and

Received: 2016-03-31 Accepted: 2016-04-30

Foundation: National Natural Science Foundation of China, No.41671082

Author: Jin Xiaobin (1974-), specialized in land use and land planning. E-mail: jinxb@nju.edu.cn 
natural ecologies and can aid in the understanding of these interactions (Sterling et al., 2013; Liu et al., 2014).

Land cover change motivated by human activities has been influencing the weather and ecosystem globally and regionally, which becomes a hot spot of international attentions. As an essential aspect of research on Land Use and Cover Change (LUCC) (Turner et al., 1995; Steffen et al., 2005; Voldoire et al., 2007), historical LUCC can supplement contemporary remote sensing data with reconstructed historical information to facilitate the identification of LUCC progress, which may provide credible reference/evidence support to simulate land use and weather changes and draft a sustainable development strategy.

Up to now, the subject of most researches on historical LUCC has steadily been farmland. In terms of the spatial scale, both global and regional have been covered. Specifically, researches at the global scale focus on characteristics and trends of global land use change and are of low accuracy, which is typically represented by SAGE (Ramankutty and Foley, 1998; Ramankutty and Foley, 1999; Ramankutty and Foley, 2010), HYDE (Goldewijk, 2001; Goldewijk and Van, 2006; Goldewijk et al., 2011), Pongratz et al. (2008) etc.; researches at the regional scale are more likely to be interested in exploring the utilization pattern of national/regional land use, emphasize data accuracy and methodology suitability, which can further be divided into continental/national (Ge et al., 2008; Ge, 2008; Hall et al., 1995; He et al., 2007; Kaplan et al., 2009; Liu and Tian, 2010; Steyaert and Knox, 2008), provincial/regional (Ge et al., 2003; He et al., 2012; Li et al., 2011; Li et al., 2012; Li et al., 2014; Lin et al., 2009; ; Ye et al., 2009a; Ye et al., 2009b; Zhang and Chen, 2007; Zhang et al., 2015), and prefecture/county levels (Bai et al., 2007; Lu et al., 2010; Wang et al., 2013).

In terms of the organization of spatial data, these researches have been carried out based on either the administrative setting or the spatial grid. The administrative setting includes the boundary at provincial, prefecture or county levels (Ge et al., 2008a; He et al., 2007; Lu et al., 2010; Wang et al., 2013; Ye et al., 2009a; Ye et al., 2009b). The grid is more about the data application and of the accuracy such as $0.5^{\circ} * 0.5^{\circ}$ (Goldewijk et al., 2011; Pongratz et al., 2008; Ramankutty and Foley, 1999; Zhang and Chen, 2007), 5'* 5' (Goldewijk and Van, 2006; Goldewijk et al., 2011), 60 km*60 km (He et al., 2012; Lin et al., 2009), $20 \mathrm{~km} * 20$ km (Steyaert and Knox, 2008), 10 km*10 km (Li et al., 2012; Liu and Tian, 2010), 2 km*2 $\mathrm{km}$ (Luo et al., 2014), 1 km*1 km (Jiang et al., 2016; Long et al., 2014; Yang et al., 2015a, 2015b; Zhang et al., 2015), 90 m*90 m (Li et al., 2011) etc. Regarding of the duration of the interested historical period, most research concentrates on the past 300 year while some international studies may trace back till 3000 (Kaplan et al., 2009) or even 12000 years ago (Goldewijk et al., 2011) and a few research related to China recovers some details about 1000 years ago (He et al., 2012; Wang et al., 2013).

As for the methodology, most of the studies summarize natural and human factors such as regional natural resource condition, population growth, and contemporary land use structure. Taking "cultivation suitability" or "reclamation availability" as core indicators, the transition probability and change rate were set for certain types of land use over specific time periods, thereby achieving "top-down" spatial distribution of corresponding land use types. The effectiveness of the reconstruction results depends upon the richness and veracity of historical data (i.e., accuracy of the number of land use types and the level of details for basic ele- 
ments in data acquisition) as well as the rationality of spatial boundary control (level of details in regional division for reconstruction and availability of historical assessment indicators). For example, contemporary population density was taken as the base map of land use pattern distribution in the global data product HYDE versions 1.1 and versions 2.0, and spatial distribution of a certain land use type was based on historical population density. The SAGE data set collected historical land statistics at a national scale. Using land use pattern interpreted from contemporary remote sensing images as a base map, the ratio of historical statistics and area data from remote sensing interpretation was used to assign historical land use types onto the base map.

Current researches have been keeping forward to reveal the spatial distribution of historical LUCC but may contain some shortcomings, for example, the reconstructed subject itself is not comprehensive, data accuracy is not thoroughly tested, spatial resolution may be too coarse, spatial variation has been neglected, etc. This study chooses Jiangsu Province in 1820 as the research subject for its detailed data records and advanced agricultural production at the time. Based on calibrated historical provincial data, characteristics of regional natural resources, research outcomes of historical geography, relationships between human and nature, and contemporary land use pattern, a comprehensive analytical framework for historical LUCC has been proposed with a resolution of $100 \mathrm{~m} * 100 \mathrm{~m}$ to reconstruct sectional LUCC pattern for Jiangsu Province in 1820 and validate it. The ultimate goal is to provide credible reference for future studies related to LUCC and global changes.

\section{Overview of the study area}

Jiangsu Province is located in East China, down streams of the Yangtze River and Huaihe River, and borders the Yellow Sea. The area has been ranked among top regions for agricultural production in the past several centuries for its mild temperature and moisture conditions, plain territories, thick soil layers, fertile soil conditions, abundant water bodies, etc. It possesses a long coast line along which land use changes significantly. The distribution of residential land varies significantly across regions. Specifically, residential land concentrates in the South along water bodies while it is relatively loosely distributed in the North. Topography effects as well so that residential lots are more likely to locate in plains rather than hilly areas (Zhai, 2008).

Jiangsu was first ever administratively as a province in 1667 (Fu, 2009) and came into its current shape by 1767 (LCCCJP, 1999). Its name, administrative boundaries, controlling areas, and location of provincial government kept changing ever since. In 1820, the time section that this study has been proposed with, there were total 12 prefectural units and these units were of three administrative ranks, i.e., eight are of "Fu", three are of "Zhou" and one is of "Ting." Specifically, eight units of "Fu" refer to Jiangning, Suzhou, Songjiang (i.e., current Shanghai), Changzhou, Zhenjiang, Yangzhou, Huaian, Xuzhou; three units of "Zhou" include Tongzhou, Haizhou, and Taicang, and one unit of "Ting" is Haimen. The administrative area of Jiangsu Province in 1820 covers the main body of current Jiangsu Province, the whole body of current Shanghai, Dangshan county, Xiao county and some minor parts of Weishan county, Suzhou, Laian county within current Anhui Province, and Chengsi county within current Zhejiang Province. For the sake of the continuity in data, this 
study mainly focuses on the part covered by current Jiangsu Province but with the administrative framework back in 1820. Therefore, the adjusted 12 administrative units in Jiangsu Province can be derived for the year 1820 (Figure 1).

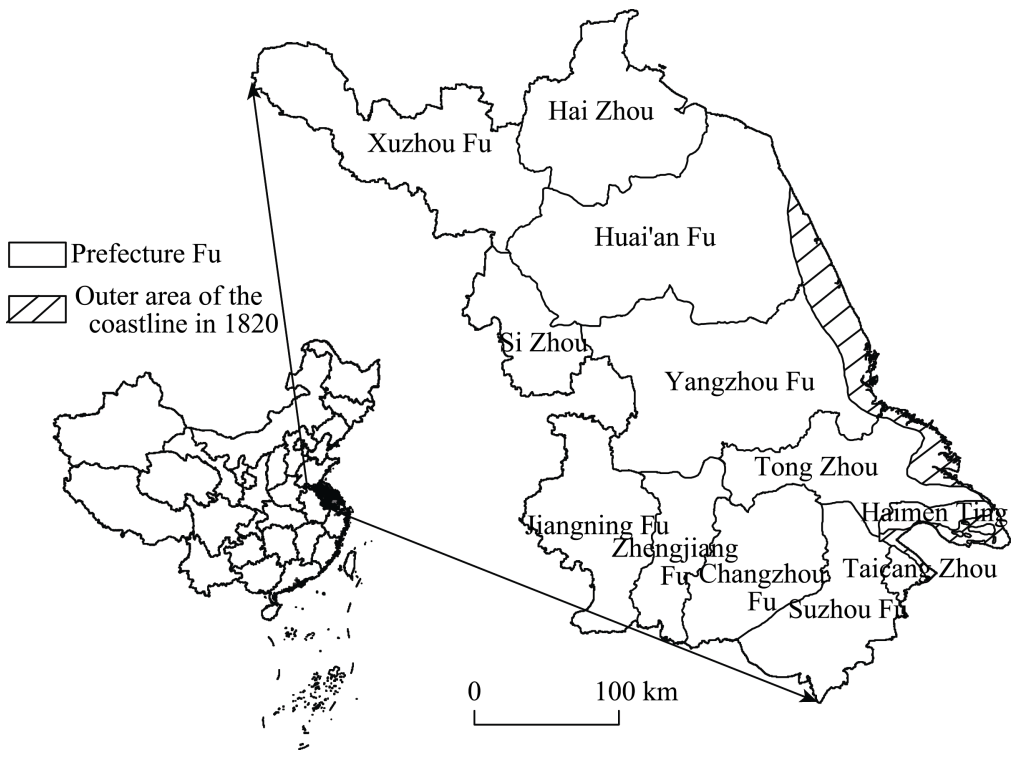

Figure 1 The location of the study area

\section{Data and methodology}

\subsection{Data}

Data in this study are of three categories: land use data, maps, and other data including population, topography and soil conditions. Some well-acknowledged historical geography research outcomes are used to avoid the statistical inconsistency or errors in recording historical data. Considering the difficulty in obtaining natural resources data in historic period, this study assumes that the status of natural factors, such as topography, soil, etc., has been stable within a century, therefore the contemporary data can be applied as an effective proxy.

\subsubsection{Land use data}

Provincial land use data for the year 1820 are from the research outcomes of Ge et al. (2003) while county-level land use data in 1932 are based on the research of Zhao (2005). Land use data in 1985 at a 100-m spatial resolution are research outcomes of land use classification based on TM image interpretation fulfilled by the Resources and Environmental Science Data Center of Chinese Academy of Sciences. Urban land use data for the year 1820 are based on research outcomes of He et al. (2002) with minor adjustments.

\subsubsection{Research units}

The vector data of historical prefecture administrative boundaries, administration centers, and water bodies are drawn from the Chinese Historical Geographic Information System (http://www.fas.harvard.edu/ chgis/). County-level administrative boundaries in 1820 (Niu, 
1990) are obtained by adjusting data in 1911 considering few changes during 1820 and 1911 in county settings. Contemporary administrative boundaries are extracted from the National Primary Geographic Information System (http://nfgis.nsdi.gov.cn/nfgis/chinese/c_xz.htm).

\subsubsection{Other data}

1) Demographic data for individual administrative units in 1820 are obtained from the Chinese Demographic History (the 5th volume.) (Cao, 2005). City-level demographic data and non-farming population data during 1984 and 1986 are from Fifty Years of Jiangsu Province: 1949-1999. Urban population data in 1820 are adjusted once based on research outcomes of Cao (2002), Fan (1990), and Wang (1984).

2) Topographic data, i.e., elevation and slope, are from the ASTER GDEM V1 with a 30-m spatial resolution accuracy provided by the International Scientific Data Mirror Site (http://datamirror.csdb.cn).

3) Soil data are acquired from the Chinese Soil Information System (SIS China) with a 2-km spatial resolution based on results of the Second National Soil Survey (1980).

Because these multi-source data are differentiated with each other in terms of scope, scale and coordinate, some pre-adjustments, such as projection conversion, stitching and cutting, resampling, raster and vector data conversions, and spatial interpolation are necessary. Finally, all data are re-projected into the WGS- 84 coordinate system and all raster data are resampled into $100 \mathrm{~m} * 100 \mathrm{~m}$ grids.

\subsection{Spatial specification for reconstruction and land use classification}

\subsubsection{Spatial specification for reconstruction}

To effectively representing the historical characteristics of rural residential areas, considering the average area of rural residential units in contemporary Jiangsu Province (Tian et al., 2002), as well as in combination with the contemporary land use data accuracy for inversion, this study specifies the grid dimension to be $100 \mathrm{~m} * 100 \mathrm{~m}$.

\subsubsection{Reconstructed land use classification}

With references to land use data in Jiangsu Province in 1985, research outcomes of previous urban studies (Wang, 1984), characteristics of local land use status ( $\mathrm{Lu}$ and Ma, 2009; Shen and Ma, 1994; Wang 2009; Wu and Guo, 1994), and limitations of data, this study classifies, by integrating contemporary land use classes (Liu, 1996), the reconstructed land into four integrative primary categories, namely, farmland, residential land, water body, and other land. Specifically, residential land can be further divided into urban land and rural residential land, where urban land only covered the land within the wall of prefecture and county units. "Other land" includes forest land, grass land and unused land.

\subsection{Methodology}

Technically, the methodology includes quantitative reconstruction, spatial reconstruction, and result verification. This study mainly focuses on methodology in reconstructing farmland and residential land (including urban land and rural residential land). The overall framework of research methodology is illustrated in Figure 2. 


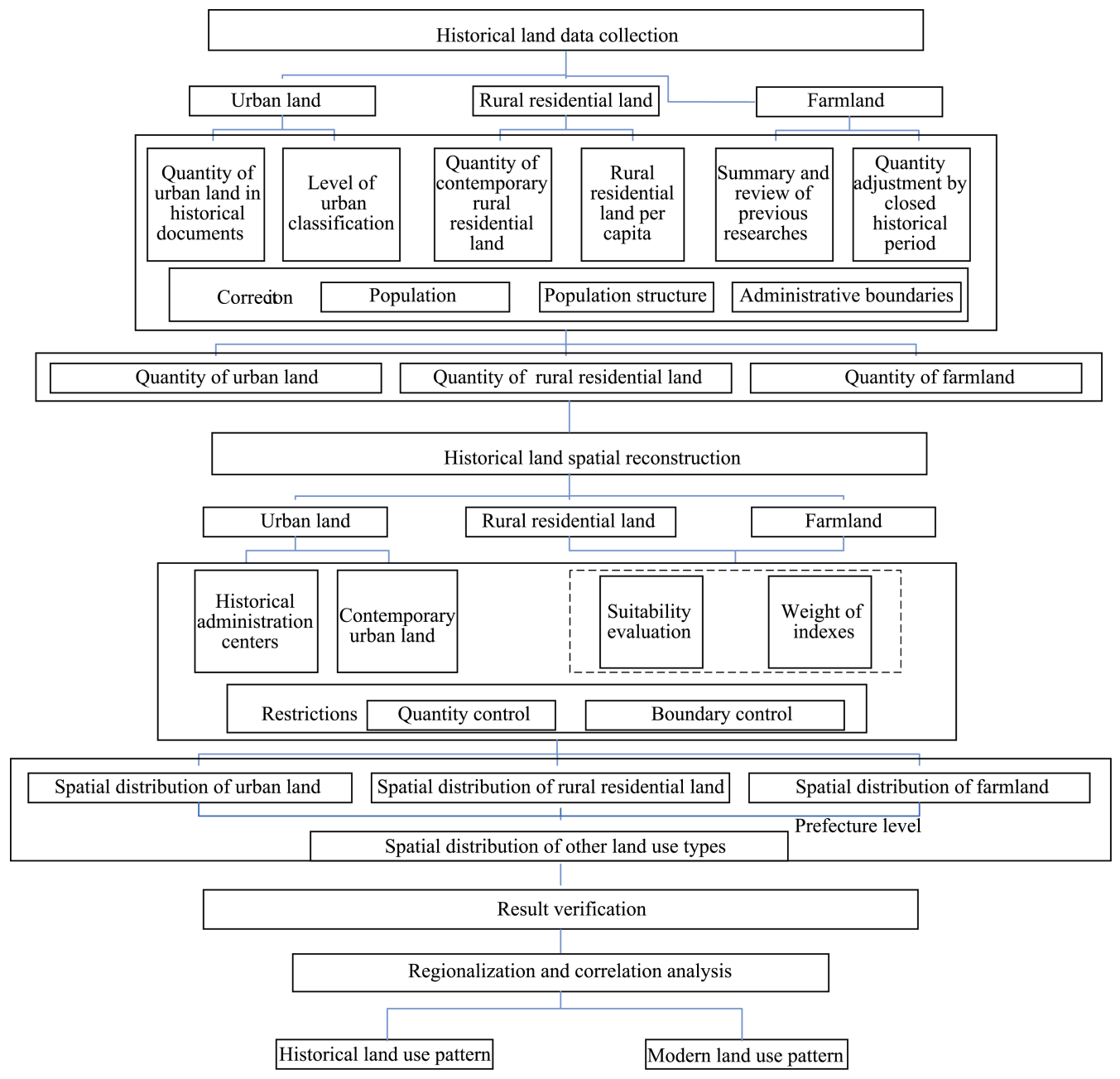

Figure 2 The technical route chart

\section{Quantitative reconstruction}

\subsection{Quantitative calibration and reconstruction of residential land}

\subsubsection{Calibration of demographic data}

We take the quantitative calibration and reconstruction as the basis and control for spatial reconstruction of historical land use pattern. The quantitative calibration and reconstruction includes both demographic and land use data. The calibration of demographic data targets at population in urban and rural areas, and the reconstruction of historical land use data covers urban land, rural residential land and farmland.

1) The data of urban residents in 12 administrative units in 1820 can be selected and calibrated from outcomes of research on ancient urban studies and demography within Jiangsu Province (Cao, 2002; Fan, 1990; Wang, 1984) based on the desired time section and scope.

2) The data of rural residents in an administrative unit in 1820 are defined as the differ- 
ence between its total population and its urban population in 1820 .

3) The number of urban residents for an administrative unit in 1985 can be defined as the product of the unit's total population and the proportion of rural residents. To reduce the randomness, the proportion of rural residents is defined as the average value from the year 1984 to the year 1986.

4) Data of rural residents in an administrative unit with adjusted administrative boundaries can be calculated based on population density weighted by unit area as shown by the following formulas:

$$
\begin{gathered}
P R_{i}(1820)=P T_{i}(1820)-P U_{i}(1820) \\
P R_{i}(1985)=P T_{i}(1985) \cdot\left[1-\frac{1}{3} \cdot \sum_{j=1984}^{1986} \frac{P U_{i}(j)}{P T_{i}(j)} 1-\frac{1}{3} \cdot \sum_{j=1984}^{1986} \frac{P U_{i}(j)}{P T_{i}(j)}\right] \\
R P R_{i}(t)=\sum_{j=1}^{n} \frac{P R_{i j}(t)}{S_{i j}} \sum_{k=1}^{m} S_{i j k}
\end{gathered}
$$

where

$P R_{i}(1820)$ is the number of rural residents in unit $i$ in 1820 ;

$P T_{i}(1820)$ is the total population in unit $i$ in 1820 ;

$P U_{i}(1820)$ is the number of urban residents in unit $i$ in 1820 ;

$P R_{i}(1985)$ is the number of rural residents in unit $i$ in 1985;

$P T_{i}(j)$ is the total population in unit $i$ in the year $j$;

$P U_{i}(j)$ is the number of rural residents in unit $i$ in the year $j$;

$t$ indicates the study year, either 1820 or 1985 ;

$R P R_{i}(t)$ is the number of rural residents in unit $i$ in the year $t$;

$P R_{i j}(t)$ is the number of rural residents in unit $j$ which shares common space with unit $i$ the in the year $t$;

$S_{i j}$ is the amount of area in unit $j$;

$S_{i j k}$ is the amount of area of $k$ in unit $i$ but shall be readjusted to unit $j$;

$m$ is the number of polygons located within unit $i$ but shall be adjusted to unit $j$;

$n$ is the number of units which share some space with unit $i$.

\subsubsection{Quantitative reconstruction of rural residential land}

Very few studies have ever been conducted to reveal the amount of historical rural residential areas. Before the 1980s, social and economic development in China had been with low growth rates (Tang and Yao, 1999); confined by both the economic conditions and strict restriction on population mobility, urban development and urbanization had been progressed slowly and therefore the rural residential pattern had been of little change. In this case, it is reasonable to assume that per capita rural residential land in a unit had been stable between 1820 and 1985 and the area of rural residential land in 1820 can be calculated based on the formula below:

$$
G_{i}(1820)=\frac{R P R_{i}(1820) \cdot G_{i}(1985)}{R P R_{i}(1985)}
$$

where

$G_{i}(t)$ is the amount of rural residential land area in unit $i$ in the year $t$; 
$R P R_{i}(t)$ is the number of rural residents in unit $i$ in the year $t$; and $t$ indicates the study year, either 1820 or 1985 .

\subsubsection{Quantitative reconstruction of urban residential land}

Historically, urban land was recorded based on the periphery of a city or an inner city of a county in China. Few specific studies have ever been conducted on the area of urban land. Therefore, He et al. (2002) is of significant reference value in terms of quantitatively reconstructing urban land at province, prefecture, county, i.e., three administrative levels. Moreover, the per capita urban land maintains the same at each administrative level across provinces. Considering differences in urban population across prefectures or counties or provinces, upholding the positive relationship between the scope of urban land and the size of its population, this study adjusts the amount of urban land in conformation to the proportion of urban residents. The method can be detailed in two steps:

1) Amounts of urban land in Jiangning Fu, Sizhou county in Anhui Province, and Xuyi county are directly drawn from the research outcome of He et al. (2002).

2) Amounts of urban land uses in the prefectures and counties can be derived based on the adjustments on research outcomes of He et al. (2002).

$$
\begin{gathered}
U_{i}=\frac{a \cdot m \cdot X_{i}}{\sum_{i=1}^{m} X_{i}} \\
V_{j}=\frac{b \cdot n \cdot Y_{j}}{\sum_{j=1}^{n} Y_{j}}
\end{gathered}
$$

where

$U_{i}, V_{j}$ are amounts of urban land in unit $i$ and county $j$ respectively;

$A$ and $b$ are per capita urban land areas at prefecture- and county-level respectively;

$m$ and $n$ are numbers of prefectures and counties respectively;

$X_{i}$ and $Y_{j}$ are values of urban population for prefecture $i$ and county $j$ respectively.

\subsection{Quantitative calibration and reconstruction of farmland}

Most of current available researches on historical farmland quantity focus on provincial units and employ quantitative adjustment method or estimation based on per capita farmland amount. These methods may lead to significant estimation errors due to great variations in terms of farmland quality and per capita farmland quantity within Jiangsu Province. With respect to the consistency in historical farmland changes across prefectures and counties within Jiangsu Province, this study adopts the equal-proportion method in reconstructing prefecture farmland quantity.

It is assumed that the proportion of prefecture farmland had been stable within Jiangsu Province from 1820 through 1932, which enables this study to derive the prefecture farmland quantities for individual administrative units in 1820 based on documented farmland quantity of Jiangsu Province (including Shanghai) in 1820 and county-level farmland statistics in 1932. It is necessary to have these prefecture farmland amounts adjusted according to 
changes of administrative boundaries. Especially, farmland area may change in some areas in the process of adjusting historical administrative boundaries to current prefecture administrative boundaries. These areas are so called adjusted areas in this study.

Therefore, the reconstruction of prefecture farmland quantity can be inferred as:

(1) Prefecture farmland amount before adjusting administrative boundaries can be calculated by formula 7 .

$$
Y_{h, i}=\frac{X_{h, i} \cdot Y_{h}}{\sum_{h=1}^{2} \sum_{i=1}^{n} X_{h, i}}
$$

where

$h=1$ refers to Sizhou city in Anhui Province while $h=2$ refers to cities in Jiangsu Province in 1820 ;

$Y_{h, i}$ is the amount of farmland in 1820 in city $i$;

$X_{h, i}$ is the amount of farmland in 1932 in city $i$;

$Y_{h}$ is the farmland amount in province $h$ in the year 1820; and

$n$ is the number of administrative units in this study.

(2) Farmland quantity adjusted upon administrative boundaries can be calculated by the following formulas:

$$
\begin{gathered}
R_{j}=\sum_{j, k=1}^{n}\left(\alpha_{j} \cdot \beta_{k}\right) \\
Y R_{h, i}=Y_{h, i} \cdot \sum_{j=1}^{m}\left(1+\lambda \cdot R_{j}\right)
\end{gathered}
$$

where

$R_{i}$ is an adjustment parameter;

$\alpha_{j}$ is the proportion that an adjusted area takes in the county it locates;

$\beta_{k}$ is the proportion that the farmland in an adjusted area takes in the county's total farmland it locates;

$Y R_{h, i}$ is the adjusted farmland quantity in city $i$, province $h$;

$Y_{h, i}$ is the amount of farmland in 1820 in city $i$, province $h$; and

$\lambda$ indicates the direction of adjustment, i.e., $\lambda=1$ if the administrative boundaries expanded outwards since 1820 or $\lambda=-1$ is the administrative boundaries of area shrinks inwards.

\section{Spatial reconstruction}

\subsection{Spatial reconstruction of urban land}

Considering the contiguity of land uses, this study proposes three assumptions underlining spatial reconstruction for urban land.

1) Historical provincial capital, prefectures, and counties are mostly located within contemporary urban land areas and these contemporary urban lands should be continuous rather than isolated.

2) For a prefecture or county that is defined based on current administrative settings in 
current Jiangsu Province, its historical administrative boundaries in 1820 may be different and needs to be adjusted. In this study, we add all governed urban land up as a quantitative control tool and choose the closest units to current urban centers as possible historical urban land locations.

3) A few counties actually are located outside the contiguity of current urban land and need to be dealt with specifically. Referring to historical urban centers, being controlled by the quantity of corresponding urban area, current rural residential land is assumed to be possible locations for historical urban land.

\subsection{Spatial reconstruction of rural residential land}

It is rational to assume that people tend to live in the most suitable places and farm high-quality land. Therefore, this study proposes to conduct the spatial reconstruction for rural residential land and farmland based on land suitability evaluation, weighted method and quantity control.

\subsubsection{The maximum spatial distribution}

(1) Rural residential land

In this study, the contemporary setting of rural residential land and urban land (excluding areas for urban redevelopment and historical water bodies) has been assumed to be the maximum spatial distribution for historical rural residential areas, i.e., "potential rural residential areas." As to Jiangning and Suzhou where were of high-level urbanization and of great rural population density, historical rural residential areas were even beyond current residential distribution, which directly requires some data manipulations such as deletion beyond farming radius, focus statistics, general selection, random selection, and so on, to expand the maximum spatial distribution for historical rural residential areas.

(2) Farmland

The data of farmland in 1985, i.e., the time exactly before the large-scale urbanization taking place, has been assumed to be the maximum spatial distribution for historical farmland. To eliminate some gaps between residential land and farmland, unused grids after urban redevelopment have been assigned to be farmland.

(3) Hypothesis testing

All assumptions about the maximal spatial distribution of historical farmland and residential land have been tested to be valid based on the comparison between Corona images taken in the 1960s and remote sensing images (Landsat MMS) in the 1970s.

\subsubsection{Evaluation criteria}

The spatial distribution of rural residential land and farmland has been shaped by both natural conditions and human activities. With reference to outcomes of previous related studies (Jin, 1988; Lin et al., 1946; Xie and Li, 2008), evaluation criteria have been selected as listed in Table 1.

\subsubsection{Normalization of all criteria data}

The normalization method has been applied to all criteria data to eliminate dimensional effect and nonlinear effect. In case where the data will be normalized to zero, the value is actually assigned as one tenth of its minimum to facilitate the weighted calculation afterwards. 
Table 1 Suitability evaluation indices for rural residential land and farmland

\begin{tabular}{|c|c|c|c|c|}
\hline Target layer & Index layer & Property & $\begin{array}{c}\text { Weight } \\
\text { (Rural residential land) }\end{array}$ & $\begin{array}{c}\text { Weight } \\
\text { (Farmland) }\end{array}$ \\
\hline \multirow{9}{*}{$\begin{array}{l}\text { Natural } \\
\text { conditions }\end{array}$} & Elevation & Interval value & 0.256 & 0.408 \\
\hline & Slope & Interval value & 0.114 & 0.168 \\
\hline & Distance to the nearest river & Negative index & 0.100 & 0.133 \\
\hline & Soil texture & Interval value & / & 0.031 \\
\hline & $\mathrm{pH}$ value & Interval value & l & 0.015 \\
\hline & Total nitrogen & Positive index & l & 0.024 \\
\hline & Total phosphorus & Positive index & l & 0.019 \\
\hline & Total potassium & Positive index & l & 0.006 \\
\hline & Soil organic matter & Positive index & l & 0.029 \\
\hline \multirow{4}{*}{$\begin{array}{l}\text { Social and } \\
\text { economic } \\
\text { conditions }\end{array}$} & Distance to the nearest town & Negative index & 0.112 & 0.151 \\
\hline & Distance to the nearest county & Negative index & 0.077 & l \\
\hline & $\begin{array}{l}\text { The hierarchy of rural residential } \\
\text { land }\end{array}$ & Positive index & 0.340 & l \\
\hline & The concentration of farmland & Positive index & / & 0.017 \\
\hline
\end{tabular}

(1) For rural residential land

1) Elevation

The suitability for rural residential use for grids with the same elevation value is used to construct the normalization function. Meanwhile, the elevation value has been related to suitability scores and probability distribution (Yi et al., 2013). The greater the probability, the greater the suitability score. The normalization method can be illustrated by formula 10 as below.

$$
y_{i}=\frac{N\left(x_{i}\right)-N\left(x_{\min }\right)}{N\left(x_{\max }\right)-N\left(x_{\min }\right)}
$$

where

$y_{i}$ is the normalized value;

$N\left(x_{i}\right)$ is the number of contemporary rural residential land with a certain elevation value;

$N\left(x_{\min }\right)$ is the minimum number of contemporary rural residential land with a certain elevation value; and

$N\left(x_{\operatorname{man}}\right)$ is the maximum number of contemporary rural residential land with a certain elevation value.

\section{2) Slope}

Slope has been classified for each degree (i.e., $1^{\circ}$ ) and then normalized by a similar method as in dealing with elevation values.

3) Distances

Among our selected suitability evaluation items, three are distance-related indicators: the distance to the nearest village, the distance to the nearest town that a county government locates, and the distance to the nearest water bodies.

Since the distance variable may change very little when it is within a certain buffer, these 
three distance-related indicators are re-classified before being normalized. The re-classification buffer has been determined based on the average radius of villages, the average radius of towns where county governments were located, and the density of water bodies in 1820 in Jiangsu Province. The re-classified map was overlaid onto the contemporary rural residential land to derive numbers of grids within each buffer. For a village or a town, buffers are ordered incrementally and the value of buffer where the cumulative number of grids reaches $95 \%$ of the total will be set as the influence radius. For grids within such an influence radius, the distance to the nearest village, the distance to the nearest town, and the distance to the nearest water bodies will be re-classified based on intervals of $500 \mathrm{~m}, 5 \mathrm{~km}$, and $500 \mathrm{~m}$ respectively. For grids outside of an influence radius, a distance-related indicator will be assigned to a category that has been indexed as the maximal index within the influence radius plus one. After all these re-classification work, three distance-related indicators can be normalized.

4) Residential land grade

The residential land grade is defined by the area of continuous rural residential land and the distance of the grid to the geometric center of continuous rural residential land, as shown in formula (11) below.

$$
G= \begin{cases}S /(L+100)^{2} & S>10000 \\ S /(M+100)^{2} & S=10000\end{cases}
$$

where

$S$ is the area of continuous contemporary rural residential land;

$L$ is the distance of the grid to the geometric center of continuous rural residential land; and

$M$ is the minimum distance of the grid to the geometric center of its nearest rural residential land.

The addition of 100 to both $L$ and $M$ is to diminish the deviation in case the grid is too close to the geometric center of continuous rural residential land.

Such calculated $G$ values are sorted incrementally and the $G$ value where the cumulative $95 \%$ locates will be assigned to the grid as its highest residential land grade.

The similar method will be carried on in all grids within the maximum spatial distribution for rural residential land. Whereas the calculated $G$ value is greater than its highest residential land grade, the grid will be assigned with its highest residential land grade plus one as its residential land grade. Finally, all $G$ values will be normalized.

(2) For farmland

Elevation, slope, and distance-related indicators are all dealt with applying the similar methods as for rural residential land. The only difference is that maximum and minimum values are all based on contemporary farmland data.

The normalization of soil components such as $\mathrm{N}, \mathrm{P}, \mathrm{K}$, and soil texture is directed by Dang et al. (2000) while the normalization of $\mathrm{pH}$ value and soil organic matter refers to Zhou et al. (2004).

The continuity of farmland is defined by focal statistics function with 8 peripheral areas and normalized based on the number of contiguous grids. 


\subsubsection{Weights}

Weights have been determined by applying the entropy weight method to reflect the magnificence of a variable based on the difference in its observations (Guo, 2007). Weights of all indicators for rural residential land and farmland are listed side by side in table 1.

The weighted score for a grid can be calculated by applying formula 12 .

$$
W=\sum_{i=1}^{n} y_{i} w_{i}
$$

where

$y_{i}$ is the value of index $i$;

$w_{i}$ is the weight of index $i$ calculated by the entropy weight method; and

$n$ is the total units of residential land or farmland.

The grid can be labeled as "rural residential land" if its weighted score is greater with weights for rural residential land than that with weights for farmland, otherwise "farmland", and vice versa.

\subsection{Overlay}

Finally, the spatial distribution of rural residential land and farmland is derived. By overlaying related maps, the spatial land use pattern in Jiangsu Province in 1820 can be produced with a resolution of $100 \mathrm{~m} * 100 \mathrm{~m}$ as shown in Figures 3 and 4.

\section{Results}

In general, land use in Jiangsu Province in 1820 features high proportion in farming while low-proportion in non-farming uses. Meanwhile, population, topography, and the density of water bodies lead to great spatial variations in land use (Figure 5). Specifically, farmland and other non-residential uses are the main land use types in Ning-Zhen-Yang hilly area, Xu-Huai plain area, Lixia River plain area; farmland and water bodies are the main land use types in coastal plain area, plain along (a)
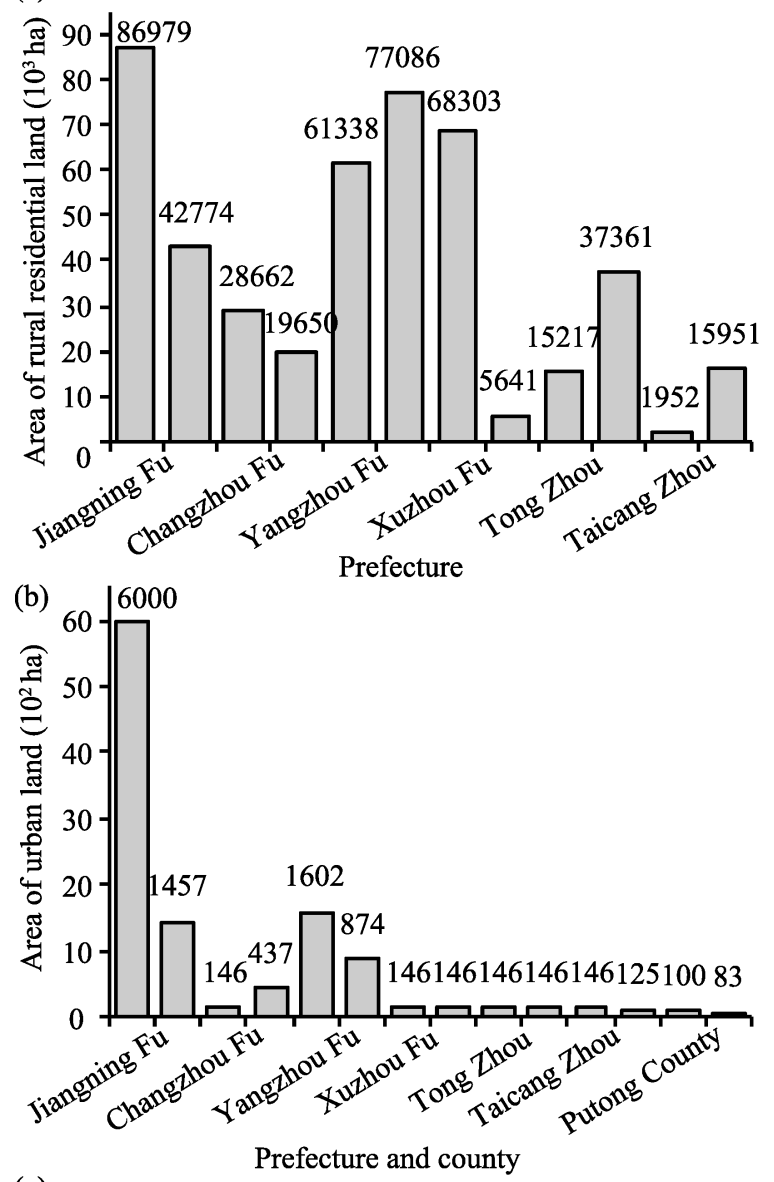

(c)

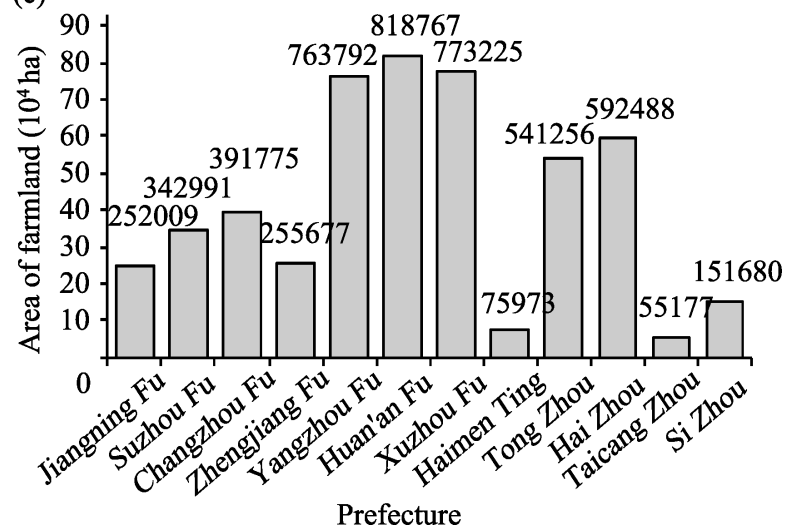

Figure 3 Rural residential land (a), urban land (b), and farmland (c) area of the study area in 1820 
the Yangtze River, Taihu Lake plain area. As to the non-farmland, the proportions of urban land use in Ning-Zhen-Yang hilly and Taihu plain areas are much higher, being $0.49 \%$ and $0.27 \%$ respectively, and the proportions of rural residential land are also high, being $6.94 \%$ and $5.21 \%$. Both the minimum proportion of urban land (i.e., $0.02 \%$ ) and the minimum proportion of rural residential land $(0.94 \%)$ occur in the coastal plain area.

The effectiveness of these reconstructed historical data cannot be directly obtained by comparing grid by grid due to the availability

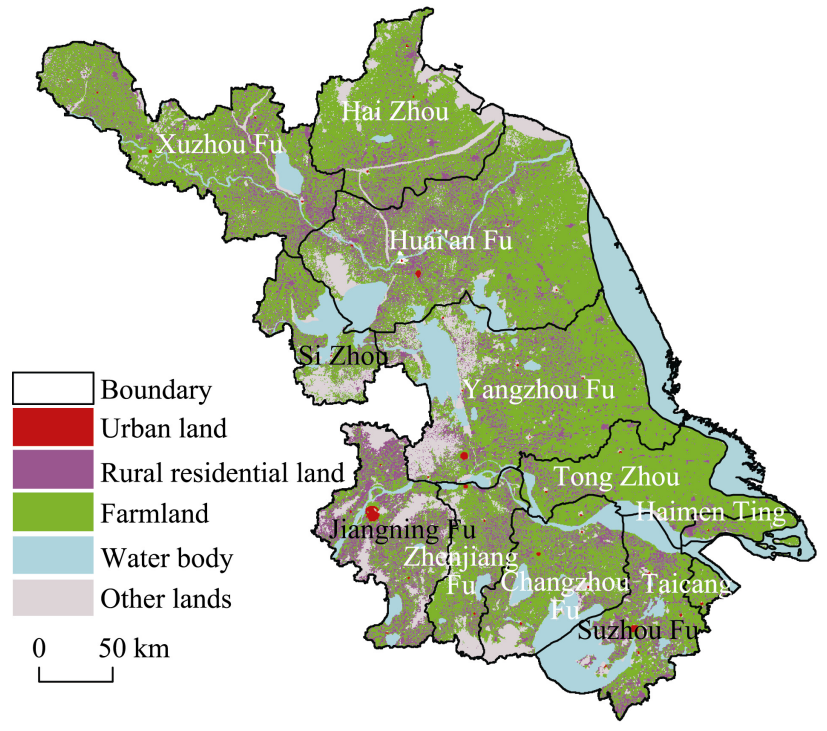

Figure 4 Spatial pattern of land use of the study area in 1820 of historical land use spatial distribution. With this study which focuses on reconstructing farmland and rural residential land based on the contemporary administrative setting of prefecture- and county-level spatial data in both 1820 and 1985 can be grouped into prefecture-level to facilitate the correlation analysis. The reconstructed land use data would be effective if farmland and rural residential land data in two groups, i.e., one in the year 1820 and the other in the year 1985, are significant positively correlated. It would be highly preferred to conduct a frequency test upon the county-level growth rate across counties to

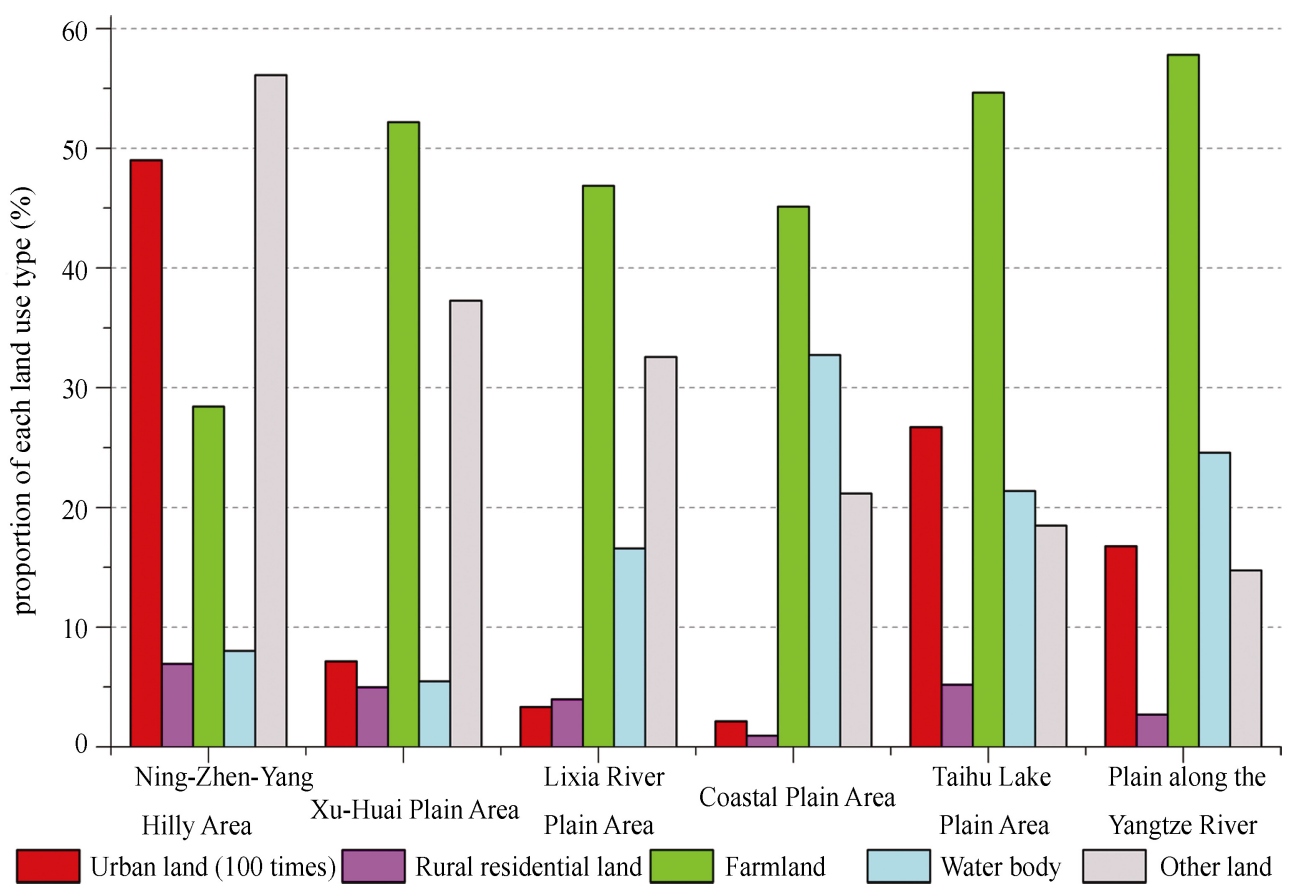

Figure 5 The land use structure of the study area in 1820 
eliminate the possibility that farmland and rural residential land grow at the similar rate in all counties. In this study, such frequency analysis shows that the mean standard deviation and the variance all changes greatly across counties and excludes the consistency or similarity hypotheses.

As in Figure 6, the correlation analysis demonstrates that farmland and rural residential land in 1820 are significantly correlated to their counterparts in 1985 with $R^{2}$ at 0.772 and 0.822 , i.e., $R$ is greater than 0.8 for both land use types. This implies the effectiveness of our reconstruction methodology and outcome.
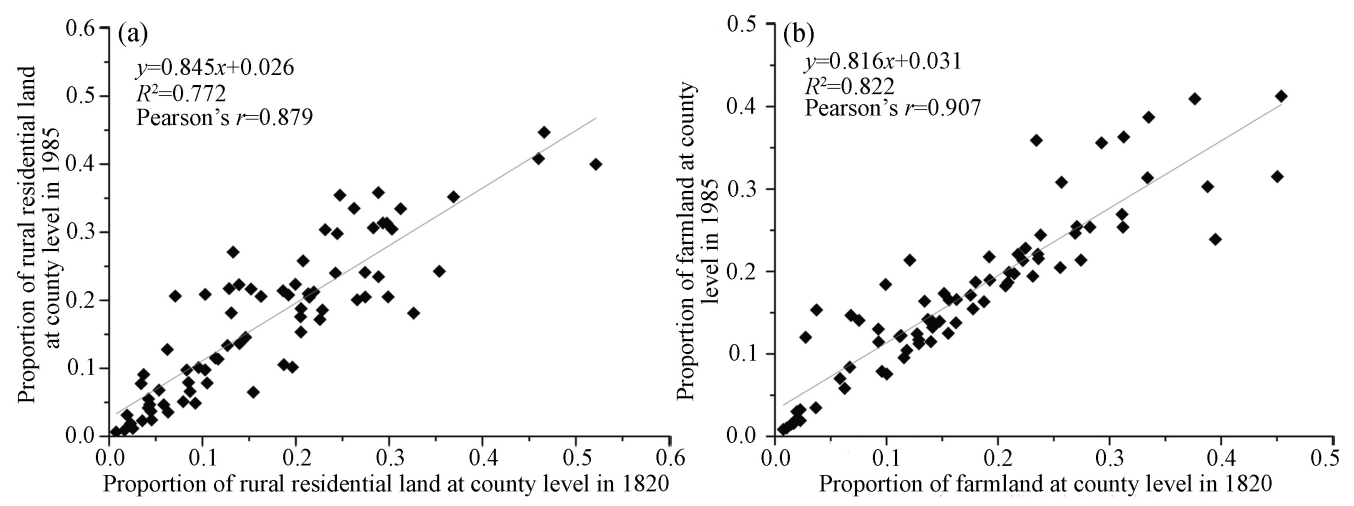

Figure 6 Correlation analysis for both rural residential land (a) and farmland (b)

\section{Conclusions}

Focusing on a certain historical period (i.e., 1820-1985), referring to the contemporary natural, social and economic conditions, this study reconstructs $100 \mathrm{~m} * 100 \mathrm{~m}$ grids of land use spatial distribution in Jiangsu Province in 1820 with four land use types, i.e., farmland, residential land, water body, and other land by setting a few theoretical assumptions and applying appropriate statistical methods. Methodology has been described in detail and has been improved by (1) incorporating a few unusual indicators, such as residential land grade, continuity of farmland; (2) integrating the effect of contiguous grids into suitability evaluation; (3) normalizing individual indicators to eliminate measurement or dimensional differences and handling maximum and minimum data specifically. Finally, the outcome has been confirmed to be an effective reconstruction attempt by applying correlation analysis with the unavailability of historical land use grids.

Restricted by the incomprehensiveness of historical data and the accuracy, this study may be not a perfectly objective attempt to reconstruct the land use pattern in 1820 . However, it is of credible reference to simulate potential historical land use spatial distribution and regional land use changes. In future, such attempts could be updated and supplemented with daily renewed historical geographic research outcomes, integrating regional development stage theories, urban-rural revolution, regionalization of land use patterns, etc. Methodology may evolve to deal with generalization, scope sensitivity, and diverse temporal features. Errors, especially sources and effects of errors, may be another critical issue to be addressed by future studies. 


\section{References}

Bai S Y, Zhang S W, Zhang Y Z, 2007. Digital rebuilding of LUCC spatial-temporal distribution of the last 100 years: Taking Dorbod Mongolian Autonomous County in Daqing City as an example. Acta Geographica Sinica, 62(4): 427-436. (in Chinese)

Cao S J, 2002. Urban population of Jiangsu Province in the Qing Dynasty. Journal of Hangzhou Normal University (Social Sciences), (4): 50-56. (in Chinese)

Cao S J, 2005. Population History of China (Volume 5). Shanghai: Fudan University Press. (in Chinese)

Dang A R, Yan S Y, Wu H Q et al., 2000. A GIS based study on the potential land productivity of China. Acta Ecologica Sinica, 20(6): 910-915. (in Chinese)

Editorial Board of Fifty Years of Jiangsu Province, 1999. Fifty Years of Jiangsu Province: 1949 to 1999. Beijing: China Statistics Press. (in Chinese)

Fan S Z, 1990. A Study on the Cities in the South of the Yangtze River during the Ming and Qing Dynasties. Shanghai: Fudan University Press. (in Chinese)

Fu L X, 2009. A new study on the establishment of Jiangsu Province in the Qing Dynasty. Studies in Qing History, 2009, (2): 23-31. (in Chinese)

Ge Q S, Dai J H, He F N et al., 2003. Analysis of cropland quantity change and driving factors of some provinces of China over the past 300 years. Progress in Natural Science, 13(8): 825-832. (in Chinese)

Ge Q S, 2008. Land Use Change and Terrestrial Carbon Budget of China over the Past 300 Years. Beijing: Science Press. (in Chinese)

Ge Q S, Dai J H, He F N et al., 2008. Land use, land cover change and carbon cycle research of China over the past 300 years. Science in China Series D: Earth Sciences, 38(2): 197-210. (in Chinese)

Goldewijk K K, 2001. Estimating global land use change over the past 300 years: the HYDE database. Global Biogeochemical Cycles, 15(2): 417-433.

Goldewijk K K, Beusen A, Van Drecht G et al., 2011. The HYDE 3.1 spatially explicit database of human-induced global land-use change over the past 12,000 years. Global Ecology and Biogeography, 20(1): $73-86$.

Goldewijk K K, Van Drecht G, 2006. HYDE 3: Current and historical population and land cover//Bouwman A F, Kram $\mathrm{T}$ and Goldewijk K K. Integrated modelling of global environmental change. An overview of IMAGE 2.4. Bilthoven: Netherlands Environmental Assessment Agency.

Guo Y J, 2007. Comprehensive Evaluation Theory, Methods and Applications. Beijing: Science Press. (in Chinese)

Hall C A S, Tian H, Qi Y et al., 1995. Modelling spatial and temporal patterns of tropical land use change. Journal of Biogeography, 22(4): 753-757.

He F N, Ge Q S, Dai J H et al., 2007. Quantitative analysis on forest dynamics of China in recent 300 years. Acta Geographica Sinica, 62(1): 30-40. (in Chinese)

He F N, Ge Q S, Zheng J Y, 2002. Reckoning the areas of urban land use and their comparison in the Qing Dynasty in China. Acta Geographica Sinica, 57(6): 709-716. (in Chinese)

He F N, Li S C, Zhang X Z, 2012. Reconstruction of cropland area and spatial distribution in the mid-Northern Song Dynasty (AD1004-1085). Journal of Geographical Sciences, 22(2): 359-370.

Kaplan J O, Krumhardt K M, Zimmermann N, 2009. The prehistoric and preindustrial deforestation of Europe. Quaternary Science Reviews, 28(27): 3016-3034.

Li X B, 1996. A review of the international research on land use/land cover change. Acta Geographica Sinica, 51(6): 553-558. (in Chinese)

Liu J Y, Kuang W H, Zhang Z X et al., 2014. Spatiotemporal characteristics, patterns and causes of land use changes in China since the late 1980s. Acta Geographica Sinica, 69(1): 3-14. (in Chinese)

Liu M, Tian H. 2010. China's land cover and land use change from 1700 to 2005: Estimations from high-resolution satellite data and historical archives. Global Biogeochemical Cycles, 24(3): B3003.

Lin S S, Zheng J Y, He F N, 2009. Gridding cropland data reconstruction over the agricultural region of China in 
1820. Journal of Geographical Sciences, 19(1): 36-48.

Jiang L Q, Zhang L J, Zang S Y et al., 2016. Accuracy assessment of approaches to spatially explicit reconstruction of historical cropland in Songnen Plain, Northeast China. Journal of Geographical Sciences, 26(2): 219-229.

Jin Q M, 1988. Rural Settlement Geography. Beijing: Science Press. (in Chinese)

Li K, He F N, Zhang X Z, 2011. An approach to reconstructing historical cropland spatial distribution with grid-boxes by utilizing MODIS land cover dataset: A case study of Yunnan Province in the Qing Dynasty. Geographical Research, 30(12): 2281-2288. (in Chinese)

Li S C, He F N, Chen Y S, 2012. Gridding reconstruction of cropland spatial patterns in Southwest China in the Qing Dynasty. Progress in Geography, 31(9): 1196-1203. (in Chinese)

Li S C, He F N, Zhang X Z, 2014. An approach to spatially explicit reconstruction of historical forest in Northeast China. Journal of Geographical Sciences, 24(6): 1022-1034.

Lin C, Lou T M, Wang C J et al., 1946. Geographical survey of the Jialing River Basin (Volume 2). Geographical Special Issue, (1): 105-135. (in Chinese)

Liu J Y, 1996. Macro-scale Survey and Dynamic Study of Natural Resources and Environment of China by Remote Sensing. Beijing: China Science and Technology Press. (in Chinese)

Local Chronicles Compilation Committee of Jiangsu Province (LCCCJP), 1999. Jiangsu Provincial Annals: Geography Annals. Nanjing: Jiangsu Ancient Book Press. (in Chinese)

Long Y, Jin X B, Yang X H et al., 2014. Reconstruction of historical arable land use patterns using constrained cellular automata: A case study of Jiangsu, China. Applied Geography, 52: 67-77.

Lu X Q, Ma J, 2009. City within the city walls: Rethinking the seat city form of ancient China. Social and Economic History of China, (2): 7-16. (in Chinese)

Lu Y, Zhang S W, Yang J C, 2010. Application of toponymy to the historical LUCC researches in Northeast China: Taking Zhenlai County of Jilin Province as an example. Geo-information Science, 12(2): 174-179. (in Chinese)

Luo J, Zhang Y L, Liu F G et al., 2014. Reconstruction of cropland spatial patterns for 1726 on Yellow River-Huangshui River Valley in northeast Qinghai-Tibet Plateau. Geographical Research, 33(7): 1285-1296. (in Chinese)

Niu P H, 1990. Comprehensive Table of Administrative Evolution of the Qing Dynasty. Beijing: Sinomaps Press. (in Chinese)

Pongratz J, Reick C, Raddatz T et al., 2008. A reconstruction of global agricultural areas and land cover for the last millennium. Global Biogeochemical Cycles, 22: GB3018. doi: 10.1029/2007GB003153.

Ramankutty N, Foley J A, 1998. Characterizing patterns of global land use: An analysis of global croplands data. Global Biogeochemical Cycles, 12(4): 667-685.

Ramankutty N, Foley J A, 1999. Estimating historical changes in global land cover: Croplands from 1700 to 1992. Global Biogeochemical Cycles, 13(4): 997-1027.

Ramankutty N, Foley J A. ISLSCP II Historical Croplands Cover, 1700-1992. In: Hall F G, Collatz G, Los S et al. (eds.). ISLSCP Initiative II Collection. Data set. Available on-line [http://daac.ornl.gov/] from Oak Ridge National Laboratory Distributed Active Archive Center, Oak Ridge, Tennessee, USA, 2010.

Shen W X, Ma T L, 1994. Utilization, problems and solutions of forest resources of Jiangsu Province. Forest Resources Management, (4): 50-53. (in Chinese)

Steffen W, Sanderson R A, Tyson P D et al., 2005. Global Change and the Earth System: A Planet under Pressure. New York: Springer-Verlag.

Sterling S. M., Ducharne A., Polcher J. 2013. The impact of global land-cover change on the terrestrial water cycle. Nature Climate Change, 3(4): 385-390.

Steyaert L T, Knox R G. 2008. Reconstructed historical land cover and biophysical parameters for studies of land-atmosphere interactions within the eastern United States. Journal of Geophysical Research: Atmospheres, 113. doi: $10.1029 / 2006 J D 008277$.

Tang M L, Yao S M, 1999. On the development of urbanization in Jiangsu Province: Process and characteristics. 
Economic Geography, 19(4): 117-122. (in Chinese)

Tian G J, Liu J Y, Zhang Z X et al., 2002. The scale distribution characteristics of Chinese rural settlements by remote sensing and GIS. Journal of Remote Sensing, 6(4): 307-312. (in Chinese)

Turner B L, Skole D L, Sanderson S et al., 1995. Land-use and Land-cover Change Science/Research Plan. Stochkholm: IGBP.

Voldoire A, Eickhout B, Schaeffer M et al., 2007. Climate simulation of the twenty-first century with interactive land-use changes. Climate Dynamics, 29(2): 177-193.

Wang G S, Jie Y W, Wang X Q et al., 2013. Data reconstruction of Heihe River Basin cultivated land area prior to the Ming Dynasty. Resources Science, 35(2): 362-369. (in Chinese)

Wang S H, 1984. Regional studies of China's modernization: Jiangsu Province (1860-1916). Taipei: Institute of Modern History, Academia Sinica. (in Chinese)

Wang S S, 2009. Study on the structure of construction land in Chinese ancient city based on the analysis of Hejin and Hancheng. Journal of Xi'an University of Architecture \& Technology (Natural Science Edition), 41(3): 391-396. (in Chinese)

Xie H L, Li B, 2008. Driving forces analysis of land-use pattern changes based on logistic regression model in the farming-pastoral zone: A case study of Ongiud Banner, Inner Mongolia. Geographical Research, 27(2): 294-304. (in Chinese)

Yang X H, Jin X B, Guo B B et al., 2015a. Research on reconstructing spatial distribution of historical cropland over 300 years in traditional cultivated regions of China. Global and Planetary Change, 128: 90-102.

Yang X H, Guo B B, Jin X B et al., 2015b. Reconstructing spatial distribution of historical cropland in China's traditional cultivated region: Methods and case study. Chinese Geographical Science, 25(1): 1-15.

Ye Y, Fang X Q, Ren Y Y et al., 2009a. Coverage changes of cropland in northeastern China during the past 300 years. Science in China Series D: Earth Sciences, 39(3): 340-350. (in Chinese)

Ye Y, Fang X Q, Zhang X Z et al., 2009b. Coverage changes of forestland and grassland in northeastern China during the past 300 years. Journal of Beijing Forestry University, 31(5): 137-144. (in Chinese)

Yi H M, Zhou S L, Wu S H et al., 2013. An integrated assessment for regional heavy metal contamination in soil based on normal fuzzy number. Acta Scientiae Circumstantiae, 33(4): 1127-1134. (in Chinese)

Zhai L S, 2008. Integrated Natural Zoning and Architecture Systems of Provincial Town Architecture of China: Theory and Practice of Jiangsu, Guizhou and Hebei Provinces. Beijing: Geological Press. (in Chinese)

Zhao Y, 2005. Land use and driving force of the Region of Su-Wan (1500-1937) [D]. Shanghai: Fudan University. (in Chinese)

Zhang J, Chen X, 2007. The historical land use and vegetation cover change in eastern China. Journal of Nanjing University (Natural Sciences), 43(5): 544-555. (in Chinese)

Zhang L J, Jiang L Q, Zhang X Z, 2015. Spatially precise reconstruction of cropland areas in Heilongjiang Province, Northeast China during 1900-1910. Journal of Geographical Sciences, 25(5): 592-602.

Zhou R, 2001. A general inspection and re-appraise on area under cultivation in the early period of the Qing. The Journal of Chinese Social and Economic History, (3): 39-49. (in Chinese)

Zhou Shenglu, Li Ruhai, Wang Liyang et al., 2004. Farmland Classification Research of Jiangsu Province. Nanjing: Southeast University Press. (in Chinese) 